\title{
Investigating the Melting Behaviour of Polymorphic Zeolitic Imidazolate Frameworks
}

Received 00th January 20xx, Accepted 00th January 20xx

\author{
Alice M. Bumstead, ${ }^{a}$ María Laura Ríos Gómez, ${ }^{\mathrm{a}, \mathrm{b}}$ Michael F. Thorne, ${ }^{\mathrm{a}}$ Adam F. Sapnik, ${ }^{\mathrm{a}}$ Louis Longley, ${ }^{\mathrm{a}}$ \\ Joshua M. Tuffnell, ${ }^{a, c}$ Dean S. Keeble, ${ }^{d}$ David A. Keen ${ }^{\mathrm{e}}$ and Thomas D. Bennett ${ }^{\mathrm{a}}{ }^{\mathrm{C}}$
}

\begin{abstract}
Recently, there has been growing interest in the amorphous states of metal-organic frameworks (MOFs). Particular focus has been given to melt-quenched MOF glasses. In this work, to improve our understanding of the factors influencing melting, the thermal response of four closely related zeolitic imidazolate frameworks (ZIFs) was studied. Electron withdrawing ligands were found to lower both the melting and glass transition temperatures, providing a promising strategy for improving the processability of MOFs in the liquid state. Crucially, dense frameworks appear to be essential for melting, with their presence also initiating the melting of open pore frameworks. This opens up the rich polymorphic landscape of ZIFs to the preparation of novel MOF liquids and glasses.
\end{abstract}

\section{Introduction}

The field of metal-organic frameworks (MOFs) has developed considerably in the last 30 years. ${ }^{1-3}$ MOFs are composed of metal-containing nodes, known as secondary building units (SBUs), connected by organic linkers. ${ }^{4}$ The symmetry and connectivity of the nodes and linkers influence the resulting framework topology. ${ }^{5,6}$ The high internal surface area of MOFs along with the potential for open metal sites has prompted research into their potential applications as sorbents, catalysts and biomedical materials. ${ }^{7-11}$ Other applications as molecular sensors and redox active materials are also beginning to emerge. ${ }^{12}$ Facile solvothermal synthetic methods combined with the large number of metal nodes and organic linkers available has led to the crystal structures of over 80,000 MOFs being deposited in the Cambridge Structural Database. ${ }^{13}$

Recently, there has been growing interest in the physical properties of MOFs, with framework flexibility and defect incorporation being investigated. ${ }^{14-17}$ The thermo-mechanical stability of MOFs, and particularly the changes which occur upon exceeding the limits of stability, are also of increasing interest. Pressure or temperature induced solid-state amorphisation, i.e. structural collapse without passing through a liquid phase, has been studied in a number of structural families. ${ }^{18-21}$ Solid-liquid transitions, or melting, have also been observed in MOFs, though the majority of work centres on one family, known as zeolitic imidazolate frameworks (ZIFs). 17,22,23 Additionally, some 1D and 2D coordination polymers have been reported to melt, particularly by Horike et al..$^{24-28}$

ZIFs are composed of divalent transition metal ions connected by imidazolate $\left(\mathrm{Im}-\mathrm{C}_{3} \mathrm{H}_{3} \mathrm{~N}_{2}^{-}\right)$based linkers; they gain their name from their structural similarity to zeolites. ${ }^{29-31}$ Firstprinciples molecular dynamics simulations have demonstrated that melting of ZIFs occurs on a picosecond timescale: rapid decoordination of an imidazolate linker from a metal ion is followed by dissociation and re-coordination of a new linker in its place. ${ }^{22,32}$ The temperature at which the transition to the liquid state is complete is referred to as the melting temperature $\left(T_{\mathrm{m}}\right)$. The liquids formed upon heating can then be quenched upon cooling, yielding melt-quenched glasses. ${ }^{22,23,33}$ On re-heating, MOF glasses exhibit a glass transition $\left(T_{g}\right)$ to a liquid-like state which is reversible on cooling. ${ }^{17,23,33}$ Several MOFs have been reported to retain porosity to gases after melt-quenching and glass formation. ${ }^{34-37}$ MOF liquids and glasses are thus an exciting prospect not simply for their novelty but also for their enhanced processability, i.e. the feasibility of preparation of bulk MOF materials, compared to the more ubiquitous crystalline powders. ${ }^{22,36}$

The first example of a melting MOF was ZIF-4 [ $\left.\mathrm{Zn}(\mathrm{Im})_{2}\right]$, which crystallises in an orthorhombic $P b c a$ space group with the cag topology. ${ }^{29,33}$ It undergoes thermal amorphisation on heating above $300{ }^{\circ} \mathrm{C}$ before recrystallising to a more dense polymorph with the $14_{1} c d$ space group and the zni topology above $400{ }^{\circ} \mathrm{C} .{ }^{33,38,39}$ This polymorph then melts at $T_{\mathrm{m}}=$ $593{ }^{\circ} \mathrm{C} .{ }^{33,38,39}$

A number of mixed linker ZIFs also melt and form glasses (Table 1). Of these materials, ZIF-62 and TIF-4 crystallise in an orthorhombic Pbca space group with the cag topology (TIF tetrahedral imidazolate framework). ${ }^{29,30,40}$ However, both 
forms of ZIF-76 have a cubic crystal structure with the $P \overline{4} 3 \mathrm{~m}$ space group and the LTA topology. ${ }^{23,37}$ Interestingly, another open, cubic framework, ZIF-8 $\left[\mathrm{Zn}(\mathrm{mlm})_{2}\right] \quad(\mathrm{mlm} \quad-$ 2-methylimidazolate $\left.-\mathrm{C}_{4} \mathrm{H}_{5} \mathrm{~N}_{2}^{-}\right)$, decomposes prior to melting. ${ }^{22,32,33}$ Theoretical calculations performed by Gaillac et al. demonstrated ZIF-8 melts significantly above its experimental decomposition temperature. ${ }^{32,41}$ This is attributed to the relatively high barrier to linker diffusion between zinc tetrahedra due to the open network structure. ${ }^{22,32,33}$ It was concluded that dispersion interactions from the framework stabilise the uncoordinated linkers as they move to new metal sites during melting. ${ }^{32}$ Consequently, denser frameworks will have more dispersion interactions stabilising the linker and hence present a lower energy barrier to dissociation. ${ }^{32}$ It is clear, therefore, that framework topology and density are important factors influencing melting.

The metal centre present within a ZIF can also alter its melting behaviour. For example, a cobalt-containing analogue of ZIF-62 [Co( $\mathrm{Im})_{1.65}(\mathrm{blm})_{0.35}$ ( blm - benzimidazolate $-\mathrm{C}_{7} \mathrm{H}_{5} \mathrm{~N}_{2}{ }^{-}$) melts at a lower temperature $\left(432{ }^{\circ} \mathrm{C}\right)$ than the zinc-containing material $\left[\mathrm{Zn}(\mathrm{Im})_{1.75}(\mathrm{blm})_{0.25}\right]\left(437^{\circ} \mathrm{C}\right) . .^{34}$ However, the different stoichiometry of these two ZIFs may influence their thermal response. For example, it has recently been demonstrated that for mixed linker ZIFs composed of Im and a bulkier linker such as blm, reducing the concentration of blm in the framework can reduce the melting point of the ZIF significantly (Table 1). ${ }^{35}$ However, the complete absence of the bulky blm linker leads to the formation of ZIF-4 and a rise in the melting temperature due to recrystallisation to the zni topology prior to melting. ${ }^{33}$ Further studies on mixed linker ZIFs demonstrated that the presence of a third ligand also lowers the melting point by introducing more disorder in the crystal structure. ${ }^{42}$ These examples highlight the importance of framework chemistry on melting.

In order to expand the number of MOFs that melt prior to decomposition and find novel MOF glasses with interesting properties, the melting process must first be understood in greater depth. However, it is still unclear how factors such as crystal structure and chemistry can be used to control melting. To investigate this, four closely related ZIFs were studied: TIF$4\left[\mathrm{Zn}(\mathrm{Im})_{1.8}(\mathrm{mblm})_{0.2}\right], \mathrm{ZIF-UC-5} \quad\left[\mathrm{Zn}(\mathrm{Im})_{1.8}(\mathrm{Clblm})_{0.2}\right], \quad \mathrm{ZIF}-76-$ mblm $[\mathrm{Zn}(\mathrm{Im})(\mathrm{mblm})]$ and ZIF-76 [Zn(Im)(ClbIm)] (Fig. 1, Table 2) $\left(\mathrm{Clblm}\right.$ - 5-chlorobenzimidazolate $-\mathrm{C}_{7} \mathrm{H}_{4} \mathrm{~N}_{2} \mathrm{Cl}$, $\mathrm{mblm}-$ 5-methylbenzimidazolate $-\mathrm{C}_{8} \mathrm{H}_{7} \mathrm{~N}_{2}{ }^{-}$). These names are those reported in the literature, though the chemical compositions reported here are different due to the different synthetic methods used. ${ }^{23,30,37,40,43}$ The selection of these four materials allows the effect of both linker chemistry and crystal structure upon melting to be studied. For example, TIF-4 and ZIF-UC-5 contain different substituted benzimidazolate linkers: mblm and $\mathrm{Clblm}$. However, they both crystallise in an orthorhombic $\mathrm{Pbca}$ space group and have the cag topology. In addition, TIF-4 and ZIF-76-mbIm both contain tetrahedral zinc SBUs and Im and mblm organic linkers. However, TIF-4 crystallises in an orthorhombic $\mathrm{Pbca}$ space group with the cag topology whilst ZIF-76-mbIm crystallises in a cubic $P \overline{4} 3 m$ space group with the LTA topology.

\section{Experimental}

\section{Materials}

Imidazole (99.5\%), 5-chlorobenzimidazole (96\%) and $\mathrm{D}_{2} \mathrm{O}(20 \%$ $\mathrm{DCl})$ were purchased from Sigma Aldrich. Dimethyl sulfoxide (DMSO)- $d_{6} \quad\left(99.8\right.$ atom\% $\quad D_{1}$ contains $0.03 \% \quad(v / v)$ tetramethylsilane (TMS)) was purchased from VWR. Zinc nitrate hexahydrate (98\%) and 5-methylbenzimidazole (98\%) were purchased from Alfa Aesar. $\mathrm{N}, \mathrm{N}$-Dimethylformamide (DMF) (99.5\%) and sodium hydroxide pellets were purchased from Fischer Scientific. N,N-Diethylformamide (DEF) (99\%) and dichloromethane (DCM) (99.9\% stabilised with amylene) were purchased from Acros Organics. All materials were used without further purification.

\section{Characterisation Techniques}

Single Crystal X-ray Diffraction (SCXRD). Single crystal X-ray diffraction data on a ZIF-76-mblm crystal were collected on an Oxford Diffraction Gemini E Ultra single crystal diffractometer equipped with an Atlas CCD area detector. $\mathrm{Cu} \mathrm{K}_{\alpha}(\lambda=1.540598$ $\AA$ ) radiation was used. The experiment was performed at $298 \mathrm{~K}$ on a single crystal $(0.25 \times 0.20 \times 0.18 \mathrm{~mm})$ with a collection time of 2 hours to achieve completeness. Structure solution was performed using SUPERFLIP (a charge-flipping based program) and the refinement was performed using SHELXL both in the WinGX suite version 2018.2.44-46 See SI for full refinement details.

Table 1: Examples of ZIFs reported to melt. All values reported here are under ambient pressure. Raised pressures have been demonstrated to lower the melting point. ${ }^{47,48}$ ZIF-62 (Zn) and ZIF-62 (Co) have been reported with a range of compositions so exhibit a range of melting temperatures and glass transition temperatures.

\begin{tabular}{|c|c|c|c|c|c|}
\hline MOF & Formula & Space Group & $T_{\mathrm{m}}\left({ }^{\circ} \mathrm{C}\right)$ & $T_{\mathrm{g}}\left({ }^{\circ} \mathrm{C}\right)$ & References \\
\hline ZIF-4 & $\mathrm{Zn}(\mathrm{Im})_{2}$ & Pbca & 590 & 292 & $23,33,38,49$ \\
\hline ZIF-62 (Zn) & $\begin{array}{l}\mathrm{Zn}(\mathrm{Im})_{2-\mathrm{x}}(\mathrm{blm})_{\mathrm{x}} \\
(\mathrm{x}=0.05-0.35)\end{array}$ & Pbca & $372-441$ & $298-320$ & $23,34,35,49,50$ \\
\hline ZIF-62 (Co) & $\begin{array}{l}\mathrm{Co}(\mathrm{Im})_{2-\mathrm{x}}(\mathrm{blm})_{\mathrm{x}} \\
(\mathrm{x}=0.10-0.30)\end{array}$ & Pbca & $386-432$ & $260-290$ & $23,34,35,49,50$ \\
\hline ZIF-76 isomorphs & $\mathrm{Zn}(\mathrm{Im})_{1.62}(\mathrm{Clblm})_{0.38}$ & $P \overline{4} 3 m$ & 451 & 310 & 37,49 \\
\hline TIF-4 & $\mathrm{Zn}(\mathrm{Im})_{1.5}(\mathrm{mblm})_{0.5}$ & Pbca & 467 & 343 & 23 \\
\hline
\end{tabular}




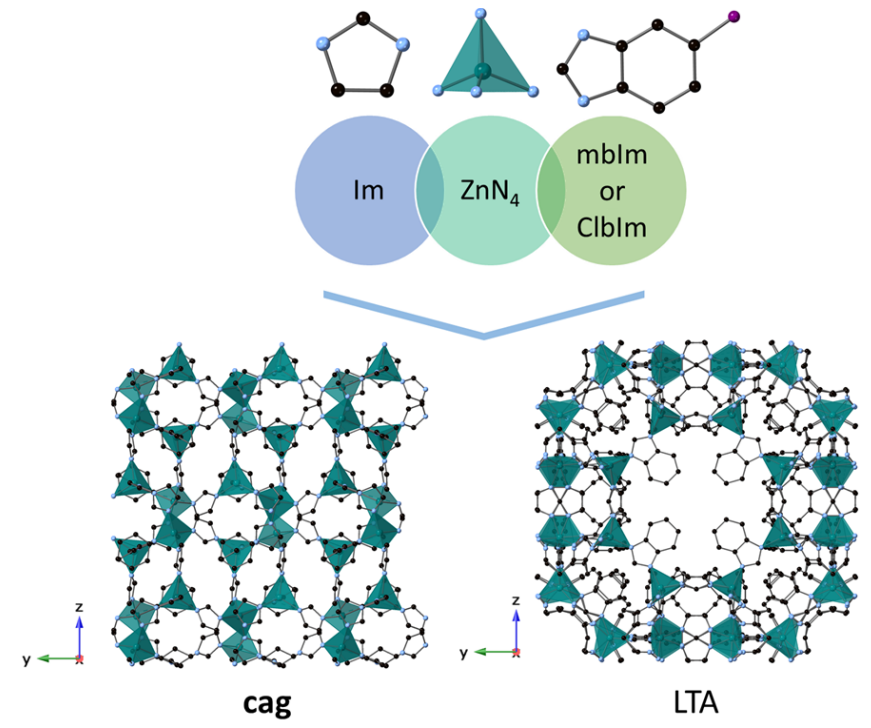

Figure 1: Comparison of the cag (TIF-4 and ZIF-UC-5) and LTA (ZIF-76-mbIm and ZIF-76) frameworks and the components of both: $\mathrm{Im}, \mathrm{ZnN}_{4}$ tetrahedra and either mblm or Clblm. Atoms shown: carbon (black), nitrogen (blue), zinc (green) and linker substituent (purple). Hydrogens omitted from all structures for clarity. Linker substituent omitted from LTA framework for clarity. Adapted from originally reported CIF files. ${ }^{30,40}$

Powder X-ray Diffraction (PXRD). Data were collected on a Bruker D8 ADVANCE diffractometer equipped with a position sensitive LynxEye detector. $\mathrm{Cu} \mathrm{K}_{\alpha}(\lambda=1.5418 \AA$ A) radiation was used. The samples were compacted into $5 \mathrm{~mm}$ disks and rotated during data collection in the $2 \theta$ range of $5-40^{\circ}$ at ambient temperature. Pawley refinements were performed using TOPAS-Academic Version 6.51 Thompson-Cox-Hastings pseudoVoigt (TCHZ) peaks shapes were used along with a simple axial divergence correction. The lattice parameters were refined against reported values for the structure in the $2 \theta$ range of 5$40^{\circ}$. The zero point error was also refined.

Differential Scanning Calorimetry (DSC). Data were collected on a Netzsch DSC 214 Polyma Instrument. Heating and cooling rates of $10{ }^{\circ} \mathrm{C} \mathrm{min}^{-1}$ were used in conjunction with a flowing argon atmosphere. Sealed aluminium pans $(30 \mu \mathrm{L})$ were used with a hole punctured in the lid to prevent pressure build-up. An empty aluminium pan was used as a reference. Background corrections were performed using the same heating cycle on an empty aluminium crucible. The melting temperature $\left(T_{\mathrm{m}}\right)$ was taken as the offset (the end point) of the melting endotherm. The glass transition temperature $\left(T_{\mathrm{g}}\right)$ was taken as the mid-point of the change in gradient of the heat flow of the DSC on the $2^{\text {nd }}$ upscan. This marks where the glass changes from a rigid to a more flexible state.

Table 2: Four ZIF systems studied in this work

\begin{tabular}{|c|c|c|c|}
\hline MOF & Formula & Space Group & Topology \\
\hline TIF-4 & {$\left[\mathrm{Zn}(\mathrm{Im})_{1.8}(\mathrm{mb} / \mathrm{m})_{0.2}\right]$} & Pbca & cag \\
\hline ZIF-UC-5 & {$\left[\mathrm{Zn}(\mathrm{Im})_{1.8}(\mathrm{Clb} / \mathrm{m})_{0.2}\right]$} & Pbca & cag \\
\hline ZIF-76-mblm & {$[\mathrm{Zn}(\operatorname{Im})(\mathrm{mblm})]$} & $P \overline{4} 3 m$ & LTA \\
\hline ZIF-76 & {$[\mathrm{Zn}(\mathrm{Im})(\mathrm{Clblm})]$} & $P \overline{4} 3 m$ & LTA \\
\hline
\end{tabular}

Thermogravimetric Analysis (TGA). Data were collected on a TA Instruments SDT-Q600 using alumina pans $(90 \mu \mathrm{L})$. Heating rates of $10{ }^{\circ} \mathrm{C} \mathrm{min}{ }^{-1}$ were used along with a flowing argon atmosphere.

${ }^{1} \mathrm{H}$ Nuclear Magnetic Resonance (NMR) Spectroscopy. ${ }^{1} \mathrm{H}$ NMR spectra were recorded at $298 \mathrm{~K}$ using a Bruker AVIII $500 \mathrm{MHz}$ Spectrometer with a dual ${ }^{13} \mathrm{C} /{ }^{1} \mathrm{H}(\mathrm{DCH})$ cryoprobe at the Department of Chemistry, University of Cambridge. All samples were dissolved in a mixture of $\mathrm{DCl}(20 \%) / \mathrm{D}_{2} \mathrm{O}$ and DMSO- $\mathrm{d}_{6}$ in a 1:5 ratio. Tetramethylsilane (TMS) was used as a reference. All data processing was performed using TopSpin 4.0.7.52

Variable Temperature Pair Distribution Function (PDF). X-ray total scattering data were collected at beamline I15-1, Diamond Light Source, UK (EE20038-2). All samples were ground and sealed in quartz capillaries ( $1.30 \mathrm{~mm}$ inner diameter). Data were collected for the background, empty capillary and for all samples to a $Q_{\max }$ of $26.0 \AA^{-1}(\lambda=0.161669 \AA$, $76.69 \mathrm{keV})$. Data were collected at 25, 100, 200,300,400,430, 450, 460 and 25 ${ }^{\circ} \mathrm{C}$ for ZIF-76-mblm with $10 \%$ beam current to minimise sample damage. Data were collected at 25, 100, 200, 300, 400, 420, 440 and $25{ }^{\circ} \mathrm{C}$ for TIF-4 with $100 \%$ beam current. Data were processed in a $Q$ range of $0.55-19.0 \AA^{-1}$ for ZIF-76-mblm and a $Q$ range of 0.50-26.0 for TIF-4. Data correction and subsequent Fourier transform was performed using the GudrunX program to obtain the PDF for each sample at each temperature. ${ }^{53,54}$

\section{Synthetic Methods}

Synthesis of TIF-4 and ZIF-UC-5. Zinc nitrate hexahydrate $(0.38$ g, $1.28 \mathrm{mmol})$, imidazole $(1.84 \mathrm{~g}, 27.0 \mathrm{mmol})$ and either 5methylbenzimidazole $(0.396 \mathrm{~g}, 3.00 \mathrm{mmol})$ or 5chlorobenzimidazole $(0.458 \mathrm{~g}, 3.00 \mathrm{mmol})$ were dissolved in $\mathrm{N}, \mathrm{N}$-dimethylformamide (DMF) $(18.8 \mathrm{ml})$ and heated at $130{ }^{\circ} \mathrm{C}$ for 48 hours. The polycrystalline powder was isolated by vacuum filtration and washed with fresh DMF. The sample was then soaked in dichloromethane (DCM) $(3 \mathrm{ml})$ for 24 hours. Excess DCM was decanted and the sample was activated by heating under vacuum at $100{ }^{\circ} \mathrm{C}$ for 3 hours. This was based on reported syntheses of TIF- 4 and ZIF-62. ${ }^{30,40,47}$

Optimisation of ZIF-76-mbIm Synthesis. Imidazole and 5-methylbenzimidazole were dissolved in a mixture of DMF $(5.75 \mathrm{ml}$ ) and $\mathrm{N}, \mathrm{N}$-diethylformamide (DEF) $(5.75 \mathrm{ml})$. Zinc nitrate hexahydrate $(0.26 \mathrm{~g}, 0.87 \mathrm{mmol})$ and sodium hydroxide solution $\left(2.5 \mathrm{~mol} \mathrm{dm}^{-3}\right)$ were added and the solution was heated at $90{ }^{\circ} \mathrm{C}$ for 120 hours (Table S1). The polycrystalline powder was collected by vacuum filtration and washed with fresh DMF. The sample was then soaked in DCM ( $3 \mathrm{ml}$ ) for 24 hours. Excess DCM was decanted and the sample was activated by heating under vacuum at $100{ }^{\circ} \mathrm{C}$ for 3 hours. This was based on reported methods for the synthesis of ZIF-76 and ZIF-76-mbIm. ${ }^{30,37,55}$

Synthesis of Phase Pure ZIF-76-mbIm and ZIF-76. Imidazole $(0.12 \mathrm{~g}, 1.76 \mathrm{mmol})$ and either 5-methylbenzimidazole $(0.11 \mathrm{~g}$, $0.83 \mathrm{mmol}$ ) or 5 -chlorobenzimidazole $(0.13 \mathrm{~g}, 0.85 \mathrm{mmol})$ were 
dissolved in a mixture of DMF $(5.75 \mathrm{ml})$ and DEF $(5.75 \mathrm{ml})$. Zinc nitrate hexahydrate $(0.26 \mathrm{~g}, 0.87 \mathrm{mmol})$ and sodium hydroxide solution ( $2.5 \mathrm{~mol} \mathrm{dm}^{-3}, 0.26 \mathrm{ml}, 0.65 \mathrm{mmol}$ ) were added and the solution was heated at $90{ }^{\circ} \mathrm{C}$ for 120 hours. The polycrystalline powder was recovered by vacuum filtration and washed with fresh DMF. The sample was then soaked in DCM (3 ml) for 24 hours. Excess DCM was decanted and the sample was activated by heating under vacuum at $100{ }^{\circ} \mathrm{C}$ for 3 hours. Based on previously reported methods. ${ }^{30,37,55}$

\section{Results and Discussion}

\section{Effect of Organic Linker Chemistry}

TIF-4 and ZIF-UC-5 were studied in order to distinguish between the effects of linker chemistry and framework topology. TIF-4 $\left[\mathrm{Zn}(\mathrm{Im})_{1.5}(\mathrm{mblm})_{0.5}\right]$ melts at $467^{\circ} \mathrm{C}$ whilst ZIF-UC-5 $\left[\mathrm{Zn}(\mathrm{Im})_{1.63}(\mathrm{Clblm})_{0.37}\right]$ melts at the lower temperature of 432 ${ }^{\circ} \mathrm{C} .23,40,43$ However, it is unclear whether this difference is caused by the different linker chemistry or by the different stoichiometry of the two materials. To address this, TIF-4 and ZIF-UC-5 were prepared by a modification of the originally reported synthesis, avoiding the use of benzene as a structure directing agent. ${ }^{40,43}$ Both crystallise in an orthorhombic Pbca space group. Phase purity and crystallinity were confirmed by $X-$ ray powder diffraction (PXRD) (Fig. S1-S2, Table S2-S3). The ratio of imidazolate to substituted benzimidazolate $\left[\mathrm{Zn}(\mathrm{Im})_{1.8}(\mathrm{Xblm})_{0.2}\right]$ for our samples was confirmed by ${ }^{1} \mathrm{H}$ NMR spectroscopy (Fig. S3-S4), a ratio that is different to those in the original reports..$^{40,43}$ One possible cause may be the alternative synthetic method used in this study. Previous calculations have demonstrated that a methyl group has a larger van der Waals volume $\left(13.67 \mathrm{~cm}^{3} \mathrm{~mol}^{-1}\right)$ than a chlorine atom $\left(12.0 \mathrm{~cm}^{3} \mathrm{~mol}^{-1}\right)$ and hence that 5-methylbenzimidazolate has a marginally larger van der Waals volume $\left(121.5 \mathrm{~cm}^{3} \mathrm{~mol}^{-1}\right)$ than 5chlorobenzimidazolate $\left(119.0 \mathrm{~cm}^{3} \mathrm{~mol}^{-1}\right) .56,57$ However, chlorine is electron withdrawing whilst a methyl group is electron donating. So, both steric and electronic effects are likely to affect melting behaviour.

The thermal response of both TIF- 4 and ZIF-UC- 5 was investigated by differential scanning calorimetry (DSC) and thermogravimetric analysis (TGA) (Fig. 2, Fig. S5-S10). TGA showed that significant mass loss for both samples occurred above $575{ }^{\circ} \mathrm{C}$ suggesting that decomposition began above this temperature (Fig. S5-S6). Both structures exhibited broad endothermic features in the DSC in the range from $150-250{ }^{\circ} \mathrm{C}$ that were associated with desolvation due to residual solvent left in the pores after activation. They also exhibited a clear endotherm coupled with a minimal loss in mass: a characteristic feature of melting. The melting temperature for TIF-4 was found at $440{ }^{\circ} \mathrm{C}$ whilst that of ZIF-UC-5 was found at $428^{\circ} \mathrm{C}$ (Fig. 2, Fig. S7-S8, Table 3). After heating above the melting offset, the samples were cooled back to room temperature and then reheated to $400{ }^{\circ} \mathrm{C}$. This yielded glass transition temperatures of 350 and $336^{\circ} \mathrm{C}$ for $a_{\mathrm{g}}$ TIF-4 and $a_{\mathrm{g}}$ ZIF-UC-5 respectively (Fig. 2 , Table 3, Fig. S9-S10). Subsequent PXRD confirmed both samples were amorphous (Fig. S11) and ${ }^{1} \mathrm{H}$ NMR spectroscopy confirmed

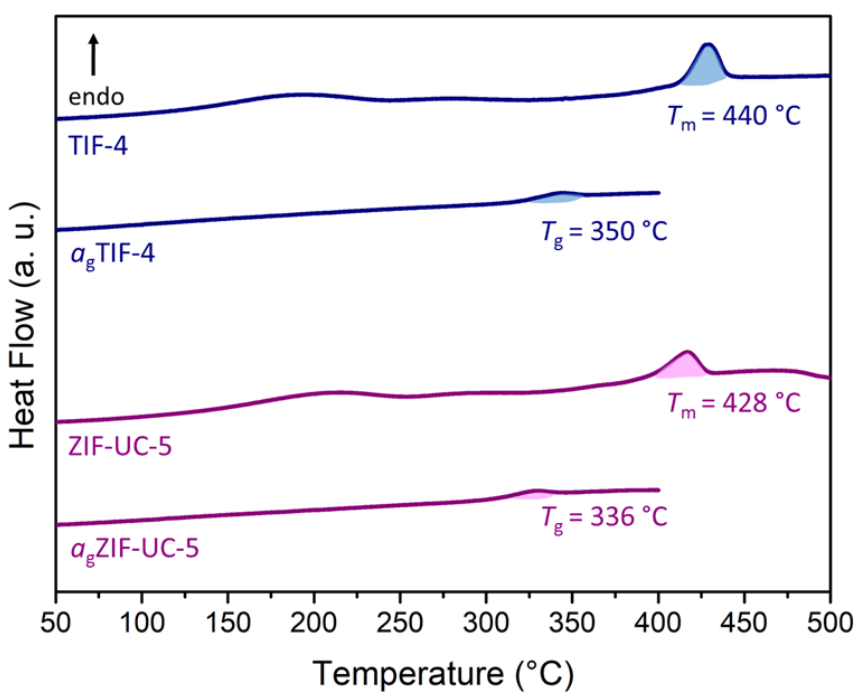

Figure 2: DSC traces of structural isomorphs: TIF-4 (blue) and ZIF-UC-5 (pink). Heat flow traces stacked by y offset. Features of interest, i.e. $T_{\mathrm{m}}$ and $T_{\mathrm{g}}$, are highlighted in the figure as a guide. The melting temperature $\left(T_{\mathrm{m}}\right)$ was taken as the offset of the melting endotherm. The glass transition temperature $\left(T_{g}\right)$ was taken as the mid-point of the change in gradient of the heat flow of the DSC on the $2^{\text {nd }}$ upscan.

both glasses had a ratio of Im to XbIm near identical to the crystalline frameworks (S12-S13). These are denoted $a_{\mathrm{g}} \mathrm{TIF}-4$

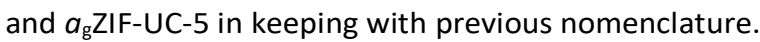

The lower melting offset of ZIF-UC- 5 compared to TIF- 4 was attributed to the electron withdrawing chlorine substituent weakening the $\mathrm{Zn}-\mathrm{N}$ coordination bond, facilitating melting. ${ }^{37}$ The lower glass transition temperature of ZIF-UC- 5 than TIF-4 was ascribed to the smaller van der Waals volume of chlorine compared to the methyl group. $37,56,57$ Hence, the dispersion forces in TIF-4 are stronger and more energy is required for the methyl groups to move past one another and for the glass to transition to a more liquid-like, mobile state. ${ }^{32,37}$ The use of halogenated linkers therefore may provide a promising strategy for lowering the melting and glass transition temperatures of MOFs.

The melting offset of TIF-4 $\left[\mathrm{Zn}(\mathrm{Im})_{1.8}(\mathrm{mblm})_{0.2}\right]\left(440{ }^{\circ} \mathrm{C}\right)$ in this work is lower than that previously reported for TIF-4 $\left[\mathrm{Zn}(\mathrm{Im})_{1.5}(\mathrm{mblm})_{0.5}\right]\left(467^{\circ} \mathrm{C}\right) .{ }^{23}$ Additionally, the melting offset of ZIF-UC-5 [Zn(Im) $\left.)_{1.8}(\mathrm{Clblm})_{0.2}\right]\left(428{ }^{\circ} \mathrm{C}\right)$ observed here is lower than the offset previously observed for ZIF-UC-5 $\left[\mathrm{Zn}(\mathrm{Im})_{1.63}(\mathrm{Clblm})_{0.37}\right]\left(\mathrm{ca} .462{ }^{\circ} \mathrm{C}\right)$. Henke et al. recently found the same phenomenon in a series of ZIF-62 MOFs of varying composition $\left[\mathrm{Zn}(\mathrm{Im})_{2-\mathrm{x}}(\mathrm{blm})_{\mathrm{x}}\right]$ : reducing the content of blm reduced the melting temperature of ZIF-62 by as much as $60{ }^{\circ} \mathrm{C} .{ }^{35}$ This was rationalised by the smaller steric hindrance of the zinc tetrahedra when less benzimidazolate was present in the framework, thus assisting the dissociation and reassociation of imidazolate linkers during melting. ${ }^{35}$ The results

Table 3: Summary of thermal data for TIF-4 and ZIF-UC-5 in this work.

\begin{tabular}{|c|c|c|c|}
\hline Sample & Composition & $T_{\mathrm{m}}\left({ }^{\circ} \mathrm{C}\right)$ & $T_{\mathrm{g}}\left({ }^{\circ} \mathrm{C}\right)$ \\
\hline TIF-4 & $\mathrm{Zn}(\mathrm{Im})_{1.8}(\mathrm{mblm})_{0.2}$ & 440 & 350 \\
\hline ZIF-UC-5 & $\mathrm{Zn}(\mathrm{Im})_{1.8}(\mathrm{Clblm})_{0.2}$ & 428 & 336 \\
\hline
\end{tabular}




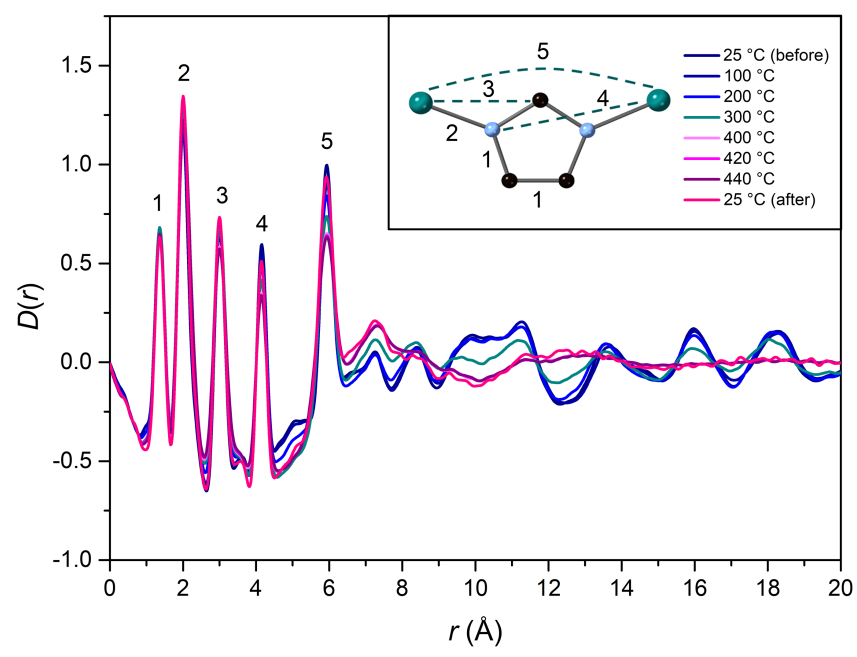

Figure 3: Pair distribution function, $D(r)$, of TIF-4 at 25, 100, 200, 300, 400, 420, 440 and $25{ }^{\circ} \mathrm{C}$. Inset shows an imidazolate ion coordinated to two zinc ions. The first five correlations are shown on this diagram. Atoms shown: carbon (black), nitrogen (blue), zinc (green)

obtained here support their work and suggest that lowering the content of the more sterically bulky linker in mixed linker MOFs is a promising strategy for lowering the melting temperature.

To investigate the thermal response of TIF-4 $\left[\mathrm{Zn}(\mathrm{Im})_{1.8}(\mathrm{mblm})_{0.2}\right]$ further, variable temperature total scattering data were collected at beamline I15-1 at the Diamond Light Source (Fig. 3, Fig. S14). TIF-4 $\left[\mathrm{Zn}(\mathrm{Im})_{1.8}(\mathrm{mblm})_{0.2}\right]$ was heated to $440{ }^{\circ} \mathrm{C}$, i.e. beyond the offset of melting. Data were collected at $\mathrm{ca} .100{ }^{\circ} \mathrm{C}$ intervals to $400{ }^{\circ} \mathrm{C}$, then at $420^{\circ} \mathrm{C}$ and $440^{\circ} \mathrm{C}$. Measurements were also taken before and after heating to allow comparison between the crystalline sample and the glass. Fourier transformation of the corrected total scattering data gave the pair distribution function $G(r)$. Here we make use of the $D(r)$ form to accentuate the high $r$ correlations (Fig. 3).

The short-range order was maintained throughout heating with the first five correlations corresponding to $\mathrm{C}=\mathrm{C} / \mathrm{C}-\mathrm{N}, \mathrm{Zn}-\mathrm{N}$, $\mathrm{Zn}-\mathrm{C}, \mathrm{Zn}-\mathrm{N}$ and $\mathrm{Zn}-\mathrm{Zn}$ (Fig. 3). These are the expected shortrange order correlations found for most ZIFs, suggesting that the sample has not decomposed on heating or exposure to the beam. ${ }^{58}$ However, the long-range order was lost at $400{ }^{\circ} \mathrm{C}$ as no clear high $r$ correlations $(r>8.0 \AA)$ are visible above this temperature. This is just below the onset of melting in the DSC trace. We ascribe the lower onset of melting in the PDF either to the presence of radiation or to the non-linear heating profile with multiple isothermal segments used to collect the total scattering data compared to the DSC data. Peaks 3-5 broaden on heating due to increasing thermal motion. We believe these correlations are more strongly affected as they correspond to longer distances in the structure than correlations 1-2. Peak height recovers on cooling suggesting thermal disorder in the crystalline and glass state are similar and that chemical connectivity is largely retained on glass formation. Together, these results support melting and glass formation of TIF-4.

\section{Optimisation of ZIF-76-mblm Synthesis}

To investigate how crystal structure influences melting, TIF-4 was then compared to ZIF-76-mblm, a structural polymorph, previously reported to melt at $471{ }^{\circ} \mathrm{C}$ of composition $\left[\mathrm{Zn}(\mathrm{Im})_{1.33}(\mathrm{mblm})_{0.67}\right] \cdot{ }^{37}$ The synthesis in the original report of ZIF-76 only gave quantities sufficient for single crystal X-ray diffraction. ${ }^{30}$ Subsequent efforts then concentrated on increasing the product yield through addition of $\mathrm{NaOH}$, resulting in various chemical compositions reported for the bulk products. ${ }^{37,55}$

Replication of the synthesis reported by Zhou et al. using $1.30 \mathrm{mmol}$ of $\mathrm{NaOH}$ led to a mixed phase product (Fig. 4, Fig. S15-S16, Table S4-S5) with additional peaks visible in the diffraction pattern (marked by asterisks). ${ }^{37}$ These additional peaks were found to index to the crystal structure of TIF-4. Peralta et al. reported that too much $\mathrm{NaOH}$ led to a mixed phase product. ${ }^{55}$ The volume of $\mathrm{NaOH}$ in the synthetic route to ZIF-76mblm was therefore varied (Fig. 4, Fig. S17-S20, Table S6-S9). Reducing the volume of $\mathrm{NaOH}$ increased the purity of the product, and omitting $\mathrm{NaOH}$ from the synthesis gave single crystals with a $6 \%$ yield. Halving the molar volume of base added, i.e. $0.65 \mathrm{mmol} \mathrm{NaOH}$, yielded ZIF-76-mblm as a phase pure product with a yield of $67 \%$ (Table S1). To confirm the structure reported previously for ZIF-76, ${ }^{30}$ a single crystal of ZIF76-mbIm was selected and the structure solved by single crystal

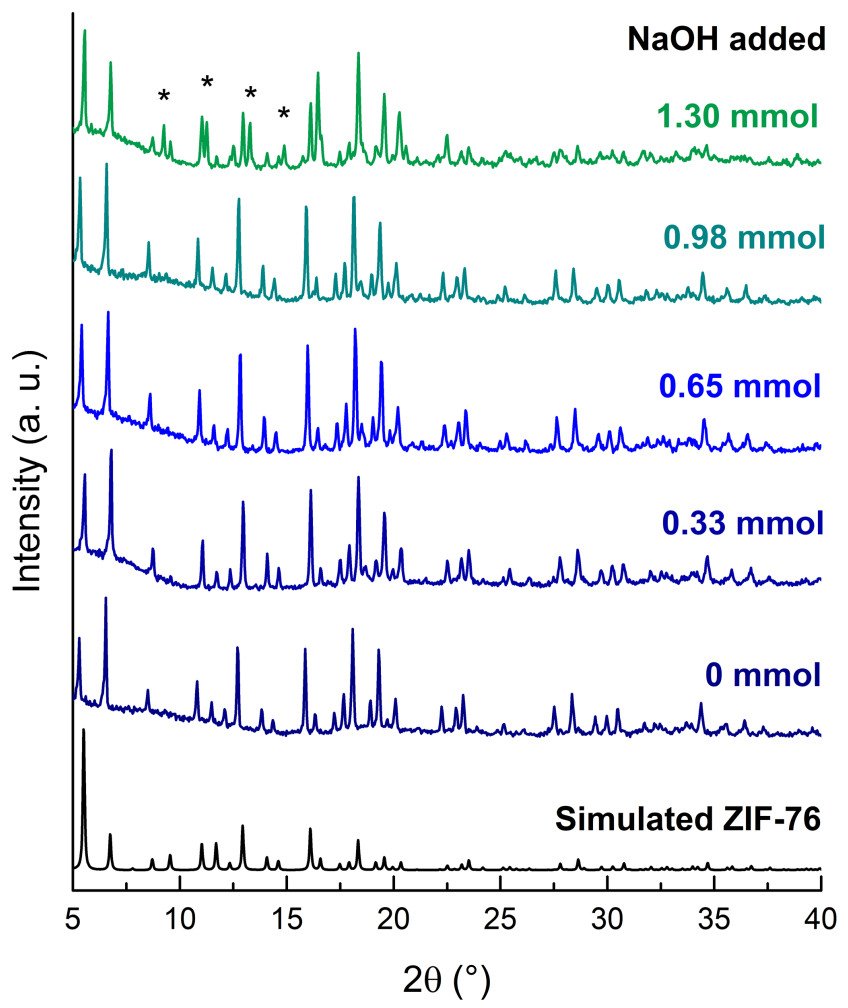

Figure 4: X-ray powder diffraction patterns of ZIF-76-mblm with varying $\mathrm{NaOH}$ in the synthesis. Reduction of the number of moles of base used in the synthesis from 1.30 $\mathrm{mmol}$ (light green) to $0 \mathrm{mmol}$ (dark blue) systematically improved the purity of the product with $0.65 \mathrm{mmol}$ providing the best combination of purity and yield. Asterisks used to highlight additional peaks in the diffraction pattern. 
$\mathrm{X}$-ray diffraction in the cubic $P \overline{4} 3 m$ space group ( $a=22.684 \AA$, $V=11672 \AA^{3}$, Table S10).

One possible explanation for the appearance of the TIF-4 phase with increasing volumes of $\mathrm{NaOH}$ may be the change in $\mathrm{pH}$ of the reaction mixture. Imidazole possesses a higher pKa (14.4) than benzimidazole type ligands (12.75). ${ }^{59}$ Increasing the $\mathrm{pH}$ of the solution through $\mathrm{NaOH}$ addition therefore results in the deprotonation of more imidazole, and facilitates inclusion within the MOF structure. This would hence favour the formation of TIF-4 as it has a higher content of imidazole in the formula unit.

The formula of ZIF-76-mblm was found by ${ }^{1} \mathrm{H}$ NMR spectroscopy to be $[\mathrm{Zn}(\mathrm{Im})(\mathrm{mblm})]$ compared to that of $\left[\mathrm{Zn}(\mathrm{Im})_{1.8}(\mathrm{mblm})_{0.2}\right]$ for TIF-4 (Fig. S21). Efforts were made to investigate the effect of lowering the ratio of $\mathrm{Im}: \mathrm{mblm}$ to provide a system of $\left[\mathrm{Zn}(\mathrm{Im})_{1.8}(\mathrm{mblm})_{0.2}\right]$ composition crystallising in an LTA topology, which could be compared to the identical composition with the cag topology, i.e. TIF-4.

Increasing the Im:mblm ratio led to immediate formation of TIF-4 as an impurity, whilst further increases resulted in the formation of TIF-4 as the only product (Fig. 5, Fig. S22-S27, Table $\mathrm{S} 11-\mathrm{S} 16)$. We rationalise this through consideration of the relative linker ratios in ZIF-76-mbIm and TIF-4, their relative energies and the symmetry constraints of the Pbca space group. To the best of our knowledge, no report has calculated the relative energies of ZIF-76-mbIm and TIF-4. However, DFT calculations on ZIFs with the formula $\left[\mathrm{Zn}(\mathrm{Im})_{2}\right]$ have revealed that the LTA topology is higher in energy than the cag

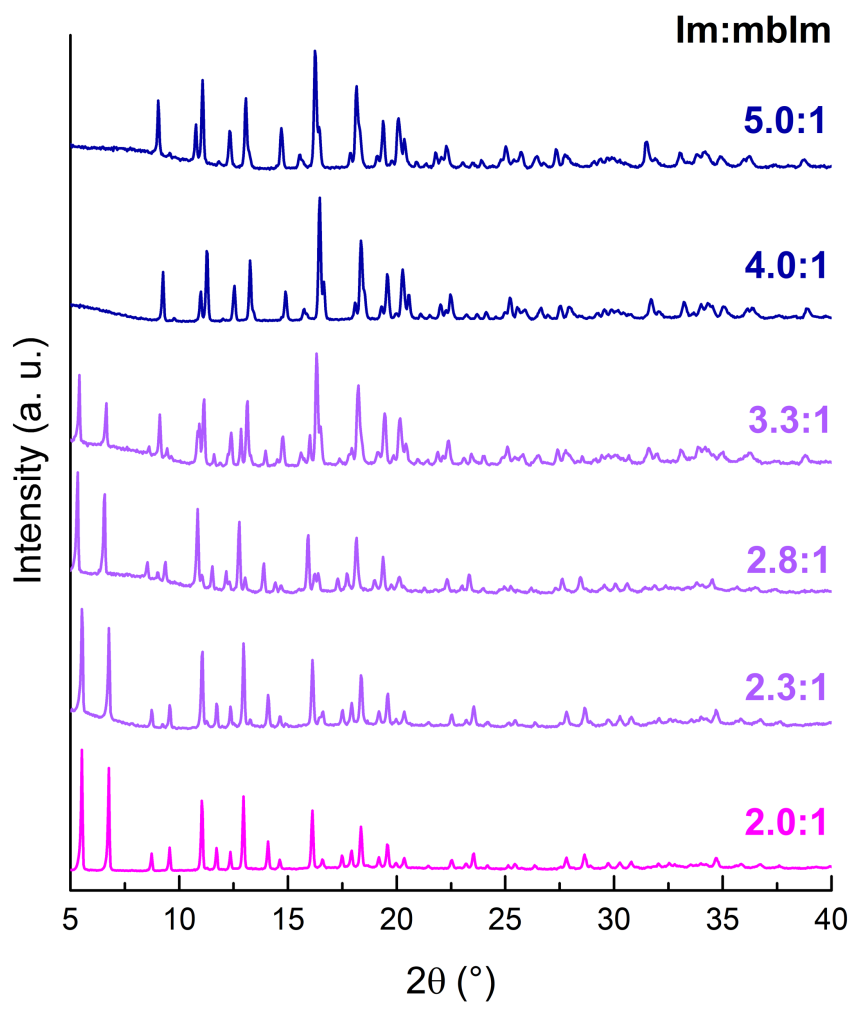

Figure 5: X-ray powder diffraction patterns of ZIF-76-mbIm. Systematically increasing the Im:mbIm ratio in the ZIF-76-mbIm synthesis from 2.0:1 to 5.0:1 gave sequentially pure ZIF-76-mbIm (pink), mixed phase ZIF-76-mbIm and TIF-4 (purple) then pure TIF4 (dark blue).

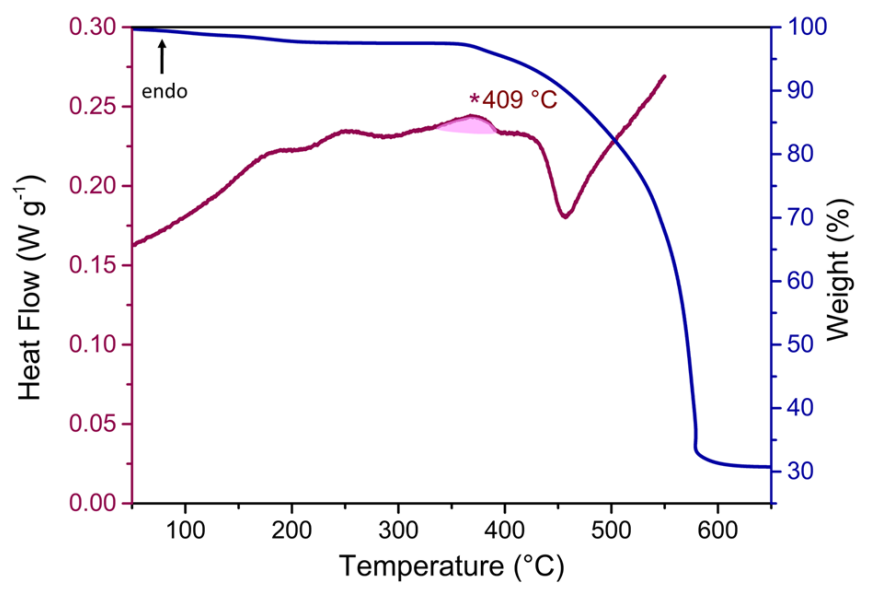

Figure 6: TGA trace of ZIF-76-mblm (blue) with significant mass loss occurring above 400 ${ }^{\circ} \mathrm{C}$. DSC trace of ZIF-76-mblm (pink) has an endothermic feature with an offset of $409^{\circ} \mathrm{C}$ (marked by an asterisk and highlighted as a guide) followed by an exotherm associated with sample decomposition.

topology. ${ }^{60,61}$ This implies that TIF-4, with the cag topology, is the more thermodynamically stable phase. Additionally, it has a much higher content of Im in its structure. Therefore, the addition of more Im immediately causes the formation of the more stable polymorph, TIF-4. Crystallographically, for the Pbca space group, asymmetric units with three or four bulky linkers have very low statistical frequencies (5\%). ${ }^{42}$ Additionally, mblm cannot have an occupancy at any site of more than 0.5 to prevent collisions. Therefore, structures with a formula with more $\mathrm{mblm}$ than $\left[\mathrm{Zn}(\mathrm{Im})_{1.5}(\mathrm{mblm})_{0.5}\right]$ are inconsistent with the Pbca space group. Hence, to accommodate more bulky mblm linker, the more porous cubic $P \overline{4} 3 m$ space group of ZIF-76$\mathrm{mblm}$ forms. Altering the linker ratio in the synthesis therefore gives subtle control over the resulting ZIF that forms.

\section{Effect of Framework Topology and Density}

The thermal response of pure phase ZIF-76-mbIm $[\mathrm{Zn}(\mathrm{Im})(\mathrm{mb} / \mathrm{m})]$ was measured (Fig. 6, Fig. S28-S29). Fluctuations in the DSC trace in the range of $150-250{ }^{\circ} \mathrm{C}$ are ascribed to desolvation of residual solvent after activation. The presence of two peaks may be due to desolvation from different sized pores in the structure. ZIF-76-mbIm $\left[\mathrm{Zn}(\mathrm{Im})_{1.33}(\mathrm{mblm})_{0.67}\right]$ (mixed phase) is reported to melt at $471{ }^{\circ} \mathrm{C}$ with a decomposition temperature of $596{ }^{\circ} \mathrm{C} .{ }^{37}$ However, the DSC trace in this work for phase pure ZIF-76-mblm $[\mathrm{Zn}(\mathrm{Im})(\mathrm{mb} / \mathrm{m})]$ does not exhibit an endotherm in the expected temperature range. A very small endotherm with a lower offset of $409^{\circ} \mathrm{C}$ was observed (Fig. 6, Fig. S29). This was followed by an exotherm accompanied with significant mass loss associated with sample decomposition.

A sequence of DSC heat treatments was performed in conjunction with ambient temperature $\mathrm{X}$-ray powder diffraction in order to determine the origin of the endotherm. Firstly, ZIF-76-mbIm was heated to $410^{\circ} \mathrm{C}$, i.e. beyond the offset of the endotherm, then cooled to room temperature (Fig. S30). X-ray diffraction after heating revealed Bragg peaks, suggesting it was still crystalline (Fig. S31, Table S17). Secondly, the sample was heated to $480^{\circ} \mathrm{C}$, i.e. within the exothermic region, then cooled to room temperature (Fig. S32). X-ray diffraction again 
contained Bragg peaks assigned to the starting ZIF-76-mblm framework (Fig. S33, Table S18). ${ }^{1} \mathrm{H}$ NMR spectroscopy confirmed that the samples of ZIF-76-mblm after heating to 410 ${ }^{\circ} \mathrm{C}$ and $480{ }^{\circ} \mathrm{C}$ had the same ratio of imidazolate to 5methylbenzimidazolate as the parent material (Fig. S34-S35). Subsequently, these samples were re-heated in the DSC to 400 ${ }^{\circ} \mathrm{C}$, i.e. above the glass transition temperature previously reported. ${ }^{37}$ However, they did not exhibit features that might readily be linked to a glass transition.

To investigate this further, variable temperature total scattering data were collected (Fig. 7, Fig. S36). Total scattering data were collected at ca. $100^{\circ} \mathrm{C}$ intervals to $400{ }^{\circ} \mathrm{C}$, then at 430 ${ }^{\circ} \mathrm{C}, 450^{\circ} \mathrm{C}$ and $460{ }^{\circ} \mathrm{C}$. Measurements were also taken at room temperature before and after heating. Conversion to the corresponding $D(r)$ revealed that long-range order, i.e. atom-atom correlations exceeding $8 \AA$, reduced markedly after $300{ }^{\circ} \mathrm{C}$ (Fig. 7a). Significant changes were also observed in the short-range order region after $200{ }^{\circ} \mathrm{C}$, i.e. for atom-atom correlations up to $8 \AA$. Comparison of a pristine sample of ZIF-76-mblm and that returned to room temperature after heating to $460{ }^{\circ} \mathrm{C}$ showed marked differences (Fig. 7b) For example, the $\mathrm{Zn}-\mathrm{N}$ correlation peak at $2 \AA$ (2) decreases in intensity, which is unexpected given the retention of $\mathrm{Zn}-\mathrm{N}$ bonding in other ZIF liquids and glasses. ${ }^{23}$ Furthermore, the $\mathrm{C}=\mathrm{C} / \mathrm{C}-\mathrm{N}$ correlation at $1.38 \AA$ (1) shifts to $1.55 \AA$, i.e. close to that expected for a $\mathrm{C}-\mathrm{C}$ single bond. ${ }^{62} \mathrm{Im}$ and $\mathrm{mblm}$ are almost exclusively composed of aromatic C-C double bonds, so the formation of more $\mathrm{C}-\mathrm{C}$ single bonds supports decomposition of the organic linkers or possible polymerisation. However, the sample changed colour in the X-ray beam from pale yellow to dark brown so decomposition may have been enhanced by beam damage. Additionally, the Zn-Zn correlation (5) decreases in intensity and broadens significantly. This is accompanied by the growth of a broad correlation centred around 5.1 A.. Again, these changes suggest that the local structure of the ZIF-76mblm framework evolves markedly on heating, hence supporting decomposition rather than melting.

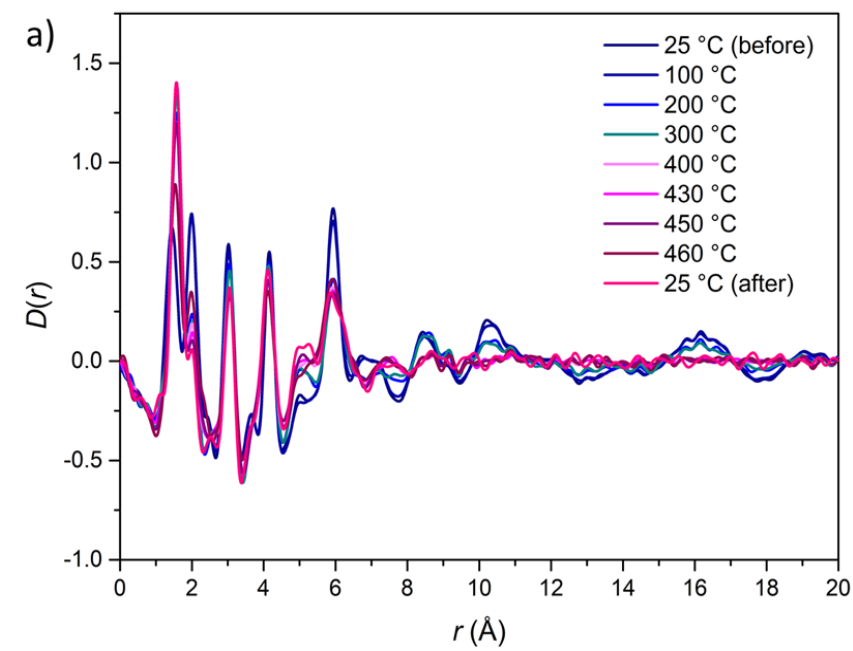

To verify the original reports by Zhou et al. of ZIF-76-mblm $\left[\mathrm{Zn}(\mathrm{Im})_{1.33}(\mathrm{mblm})_{0.67}\right]$ melting at $471{ }^{\circ} \mathrm{C}$, a sample of ZIF-76-mbIm was synthesised using the reported procedure. ${ }^{37}$ A mixed phase product (Fig. 4, Fig. S15) was prepared containing both ZIF-76-mbIm and TIF-4 with bulk composition $\left[\mathrm{Zn}(\mathrm{Im})_{1.4}(\mathrm{mblm})_{0.6}\right]$, confirmed by ${ }^{1} \mathrm{H} \mathrm{NMR}$ (Fig. S37). The thermal response of this sample was then investigated by DSC and TGA and confirmed the melting and decomposition features reported previously (Fig. S38-S39). ${ }^{37}$ This means that samples of pure ZIF-76-mblm, and samples containing a small amount of a dense polymorph impurity, behave differently upon heating. Longley et al. have reported the use of one high temperature MOF liquid, as a solvent for a secondary MOF component, which itself does not melt in the pure state under ambient pressure. ${ }^{63}$ In the glass domain, the high temperature MOF liquid would be referred to as a flux. ${ }^{63}$ They used ZIF-62 as a flux to induce melting in ZIF-8. ${ }^{63}$ As discussed earlier, Gaillac et al. concluded that ZIF-8 does not melt on its own because of the high energy barrier to linker diffusion in its open network structure. $22,32,33$

These observations can rationalise both the results in this paper and those previously reported. ${ }^{37}$ ZIF-76-mbIm, like ZIF-8, is a relatively porous, cubic framework. The barrier to linker dissociation therefore may be too high for melting to occur prior to sample decomposition. However, when TIF-4 is present as an impurity, it can assist the melting of ZIF-76-mblm by acting as a flux. These results highlight the importance of crystal structure on melting and suggest the use of impure samples may be beneficial for glass formation, providing the impurity is a dense polymorph of the major product.

\section{Effect of Organic Linker Chemistry on ZIF-76}

In a highly similar manner to ZIF-76-mblm, the dense phase polymorph ZIF-UC-5 was also found to be an impurity in synthetic routines that aimed at producing ZIF-76 in high yields

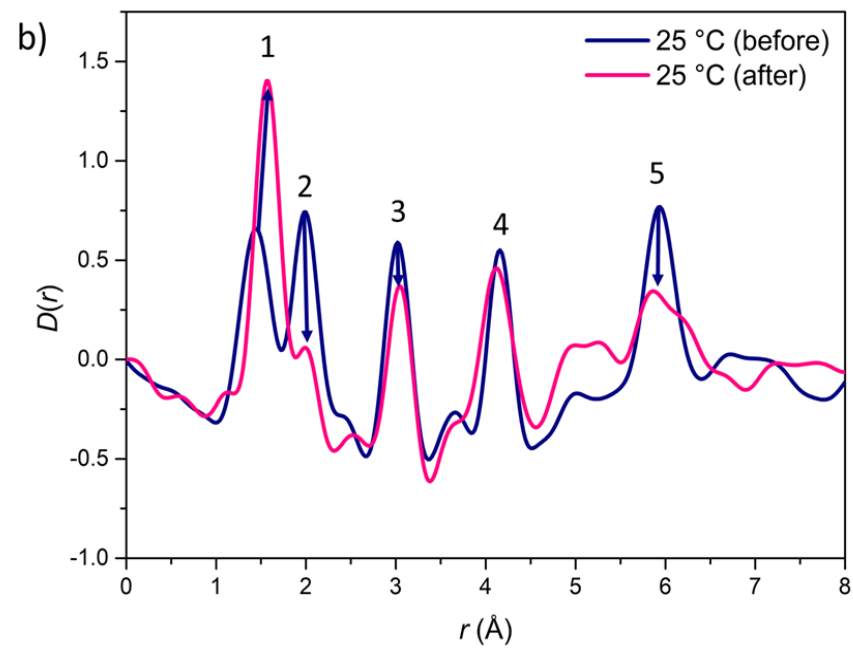

Figure 7: Variable Temperature PDF of ZIF-76-mblm a) Long-range order is lost on heating above $400{ }^{\circ} \mathrm{C}$ and this is marked by a change from blue to pink; b) Short-range order of ZIF-76-mblm before and after heat treatment. The first five correlations are labelled (see Fig. 3 for imidazolate ion with these correlations labelled). Most notably, the C-C correlation (1) shifts to higher $r$ and the $\mathrm{Zn}-\mathrm{N}$ correlation (2) decreases. The same composition of $[\mathrm{Zn}(\mathrm{Im})(\mathrm{mb} / \mathrm{m})]$ was used for the processing of all the data. However, it should be noted that as ZIF-76-mblm had begun to decompose in the X-ray beam, it is unlikely that the sample composition would have remained constant throughout heating. 


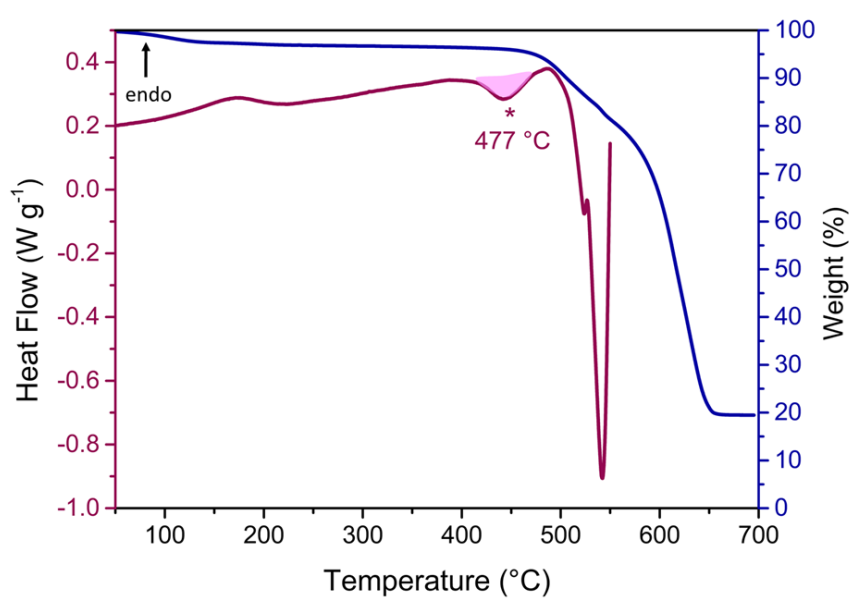

Figure 8: TGA trace of ZIF-76 (blue) with significant mass loss occurring above $450^{\circ} \mathrm{C}$. DSC trace of ZIF-76 (pink) has an exothermic feature with an offset of $477^{\circ} \mathrm{C}$ (marked by an asterisk and highlighted as a guide) followed by a larger exothermic feature associated with sample decomposition.

(Fig. S40, Table S19). ${ }^{37}$ In this previous work, ZIF-76 $\left[\mathrm{Zn}(\mathrm{Im})_{1.62}(\mathrm{Clblm})_{0.38}\right]$ was reported to melt at $451{ }^{\circ} \mathrm{C} .{ }^{37}$ The synthetic protocol which yielded pure phase ZIF-76-mblm here was adapted to obtain phase pure ZIF-76 (Fig. S41, Table S20). The chemical formula was found to be $[\mathrm{Zn}(\mathrm{Im})(\mathrm{Clblm})]$ by ${ }^{1} \mathrm{H}$ NMR (Fig. S42). Phase pure ZIF-76 $[\mathrm{Zn}(\mathrm{Im})(\mathrm{Clblm})]$ was then analysed using DSC and TGA (Fig. 8, Fig. S43-S44). It exhibited fluctuations in the DSC trace from $150-250{ }^{\circ} \mathrm{C}$ due to desolvation from residual solvent present in the pores. A small exotherm with an offset of $477^{\circ} \mathrm{C}$ was present followed by a large second exotherm associated with mass loss and decomposition. Significant mass loss began above $450{ }^{\circ} \mathrm{C}$ suggesting that phase pure ZIF-76 has similar thermal stability to the sample reported previously. ${ }^{37}$

To investigate the nature of the first exotherm at $477^{\circ} \mathrm{C}$, a sequence of DSC heating treatments were performed along with room temperature X-ray powder diffraction. Firstly, ZIF-76 was heated to $410{ }^{\circ} \mathrm{C}$, i.e. before the onset of the exotherm, then cooled to room temperature (Fig. S45). Bragg peaks were visible in the $\mathrm{X}$-ray diffraction pattern after heating, suggesting crystallinity was retained (Fig. S46, Table S21). Secondly, ZIF-76 was heated to $480{ }^{\circ} \mathrm{C}$, i.e. beyond the offset of the first exotherm but before the onset of the second larger exotherm, then cooled to room temperature (Fig. S47). However, crystallinity was lost after heating ZIF- 76 to $480^{\circ} \mathrm{C}$ as the sample exhibited diffuse scattering in the $\mathrm{X}$-ray diffraction pattern (Fig. S48). ${ }^{1} \mathrm{H} N M R$ spectroscopy confirmed that after heating to 410 ${ }^{\circ} \mathrm{C}$ and $480{ }^{\circ} \mathrm{C}$, ZIF-76 had the same ratio of imidazolate to 5chlorobenzimidazolate as the parent material (Fig. S49-S50). Subsequently, these samples were re-heated in the DSC to 400 ${ }^{\circ} \mathrm{C}$, i.e. above the glass transition temperature previously reported. ${ }^{37}$ However, there were no discernible changes in the heat flow that may be consistent with a glass transition (Fig. S45, S47).

These results further show that the presence of a dense polymorph as an impurity is essential for porous glass formation. However, the thermal behaviour of ZIF-76 in the pure state is more complex than that of ZIF-76-mbIm. The major difference is that after heating to $c a .480{ }^{\circ} \mathrm{C}$, the recovered sample of ZIF-76 is amorphous, whilst that of ZIF-76-mbIm remains crystalline. The amorphous sample of ZIF-76 does not however exhibit a glass transition. There are three possible explanations for this behaviour: (i) thermal solid-state amorphisation, which is observed in several other systems ${ }^{21}$, (ii) that the organic ligand decomposes, or (iii) the organic ligand undergoes a different structural change, i.e. rearrangement. The peak for the imidazole proton on 5-chlorobenzimidazole splits into multiple singlets on heating to $480{ }^{\circ} \mathrm{C}$ (Fig. S50) so decomposition of the linker could be a viable explanation for the loss in crystallinity. Additionally, significant mass loss begins above $450{ }^{\circ} \mathrm{C}$, which also supports sample decomposition. It is clear that subtle changes in linker chemistry have a strong influence over the thermal response of MOFs.

\section{Conclusions}

This work has used changes in linker chemistry and crystal structure to probe the resulting effects on MOF melting. It has also highlighted some promising strategies for reducing the melting temperature and glass transition temperature in ZIFs.

The control of linker chemistry over the thermal response of MOFs has been demonstrated. Changing the linker from mblm to the more electron withdrawing $\mathrm{Clblm}$ lowered the melting point from $440{ }^{\circ} \mathrm{C}$ to $428^{\circ} \mathrm{C}$ and the $T_{\mathrm{g}}$ from $350{ }^{\circ} \mathrm{C}$ to $336^{\circ} \mathrm{C}$ for the polymorphs TIF-4 and ZIF-UC-5. Additionally, changing the linker from mblm to ClbIm caused ZIF-76 to exhibit diffuse X-ray scattering prior to decomposition. It was also found that increasing the ratio of $1 \mathrm{~m}: \mathrm{mblm}$ in TIF-4 from $\left[\mathrm{Zn}(\mathrm{Im})_{1.5}(\mathrm{mblm})_{0.5}\right]$ to $\left[\mathrm{Zn}(\mathrm{Im})_{1.8}(\mathrm{mblm})_{0.2}\right]$ caused a reduction in the melting temperature from $467^{\circ} \mathrm{C}$ to $440{ }^{\circ} \mathrm{C} .23,40$

The importance of the crystal structure of the parent crystalline MOF for melting has also been demonstrated. It has been found that melting and glass formation at ambient pressure do not occur in phase pure ZIF-76 $[\mathrm{Zn}(\mathrm{Im})(\mathrm{Clblm})]$ or ZIF-76-mbIm $[\mathrm{Zn}(\mathrm{Im})(\mathrm{mblm})]$, but can be induced by the presence of a dense polymorph in the product. This melts first, and then acts as a high temperature solvent for the remaining open pore polymorph. These results are highly promising in suggesting that the rich polymorphic landscape in ZIFs may be taken advantage of to produce a range of flux-melted glasses arising from materials that do not melt in their phase pure form.

\section{Conflicts of interest}

There are no conflicts to declare.

\section{Acknowledgements}

A.M.B. acknowledges the Royal Society for funding (RGF\EA \180092) as well as the Cambridge Trust for a Vice Chancellor's Award (304253100). M.L.R.G. acknowledges project funding PAPIIT IG100618. M.F.T. would like to thank Corning Incorporated for PhD funding and project guidance. A.F.S. acknowledges the EPSRC for a PhD studentship under the 
industrial CASE scheme along with Johnson Matthey PLC (JM11106). L.L. acknowledges an EPSRC studentship. J.M.T. acknowledges funding from NanoDTC ESPSRC Grant EP/L015978/1. T.D.B. thanks the Royal Society for both a University Research Fellowship (UF150021) and a research grant (RSG $\backslash R 1 \backslash 180395)$. T.D.B. also gratefully acknowledges the EPSRC (EP/R015481/1), and the University of Canterbury Te Whare Wānanga o Waitaha, New Zealand, for a University of Cambridge Visiting Canterbury Fellowship. We extend our gratitude to Diamond Light Source, Rutherford Appleton Laboratory, U.K., for access to beamline I15-1 (EE20038-2).

\section{Notes and references}

1 H. Li, M. Eddaoudi, M. O'Keeffe and O. M. Yaghi, Nature, 1999, 402, 276-279.

2 B. F. Hoskins and R. Robson, J. Am. Chem. Soc., 1989, 111, 5962-5964.

3 S. Horike, S. Shimomura and S. Kitagawa, Nat. Chem., 2009, 1, 695-704.

4 H. Furukawa, K. E. Cordova, M. O’Keeffe and O. M. Yaghi, Science, 2013, 341, 1230444.

5 A. J. Howarth, A. W. Peters, N. A. Vermeulen, T. C. Wang, J. T. Hupp and O. K. Farha, Chem. Mater., 2017, 29, 26-39. M. Eddaoudi, D. B. Moler, H. Li, B. Chen, T. Reineke, M. O'Keeffe and O. M. Yaghi, Acc. Chem. Res., 2001, 34, 319330.

7 I. Senkovska and S. Kaskel, Chem. Commun., 2014, 50, 7089-7098.

8 O. K. Farha, A. Ö. Yazaydin, I. Eryazici, C. D. Malliakas, B. G. Hauser, M. G. Kanatzidis, S. T. Nguyen, R. Q. Snurr and J. T. Hupp, Nat. Chem., 2010, 2, 944-948.

9 A. Dhakshinamoorthy, M. Alvaro, P. Horcajada, E. Gibson, M. Vishnuvarthan, A. Vimont, J. M. Grenèche, C. Serre, M. Daturi and H. Garcia, ACS Catal., 2012, 2, 2060-2065. L. Mitchell, B. Gonzalez-Santiago, J. P. S. Mowat, M. E. Gunn, P. Williamson, N. Acerbi, M. L. Clarke and P. A. Wright, Catal. Sci. Technol., 2013, 3, 606-617.

11 P. Horcajada, R. Gref, T. Baati, P. K. Allan, G. Maurin, P. Couvreur, G. Férey, R. E. Morris and C. Serre, Chem. Rev., 2012, 112, 1232-1268.

12 A. J. Tansell, C. L. Jones and T. L. Easun, Chem. Cent. J., 2017, 11, 1-16.

13 P. Z. Moghadam, A. Li, S. B. Wiggin, A. Tao, A. G. P. Maloney, P. A. Wood, S. C. Ward and D. Fairen-Jimenez, Chem. Mater., 2017, 29, 2618-2625.

14 A. Schneemann, V. Bon, I. Schwedler, I. Senkovska, S. Kaskel and R. A. Fischer, Chem. Soc. Rev., 2014, 43, 60626096.

15 Z. Fang, B. Bueken, D. E. De Vos and R. A. Fischer, Angew. Chemie - Int. Ed., 2015, 54, 7234-7254.

16 A. K. Cheetham, T. D. Bennett, F. X. Coudert and A. L. Goodwin, Dalt. Trans., 2016, 45, 4113-4126. 440.

S. C. McKellar and S. A. Moggach, Acta Cryst., 2015, B71, 587-607.

K. W. Chapman, G. J. Halder and P. J. Chupas, J. Am. Chem. Soc, 2009, 131, 17546-17547.

T. D. Bennett, P. Simoncic, S. A. Moggach, F. Gozzo, P. MacChi, D. A. Keen, J.-C. Tan and A. K. Cheetham, Chem. Commun., 2011, 47, 7983-7985.

T. D. Bennett, D. A. Keen, J. C. Tan, E. R. Barney, A. L. Goodwin and A. K. Cheetham, Angew. Chem. Int. Ed., 2011, 50, 3067-3071.

R. Gaillac, P. Pullumbi, K. A. Beyer, K. Chapman, D. A. Keen, T. D. Bennett and F. X. Coudert, Nat. Mater., 2017, 16, 1149-1155.

T. D. Bennett, Y. Yue, P. Li, A. Qiao, H. Tao, N. G. Greaves, T. Richards, G. I. Lampronti, S. A. T. Redfern, F. Blanc, O. K. Farha, J. T. Hupp, A. K. Cheetham and D. A. Keen, J. Am. Chem. Soc., 2016, 138, 3484-3492.

D. Umeyama, N. P. Funnell, M. J. Cliffe, J. A. Hill, A. L. Goodwin, Y. Hijikata, T. Itakura, T. Okubo, S. Horike and S. Kitagawa, Chem. Commun., 2015, 51, 12728-12731. D. Umeyama, S. Horike, M. Inukai, T. Itakura and S. Kitagawa, J. Am. Chem. Soc., 2015, 137, 864-870. S. S. Nagarkar, H. Kurasho, N. T. T. Duong, Y. Nishiyama, S. Kitagawa and S. Horike, Chem. Commun., 2019, 55, 54555458.

E. T. Spielberg, E. Edengeiser, B. Mallick, M. Havenith and A. V. Mudring, Chem. Eur. J., 2014, 20, 5338-5345.

Y. J. Su, Y. L. Cui, Y. Wang, R. B. Lin, W. X. Zhang, J. P. Zhang and X. M. Chen, Cryst. Growth Des., 2015, 15, 1735-1739. K. S. Park, Z. Ni, A. P. Cote, J. Y. Choi, R. Huang, F. J. UribeRomo, H. K. Chae, M. O'Keeffe and O. M. Yaghi, Proc. Natl. Acad. Sci., 2006, 103, 10186-10191.

R. Banerjee, A. Phan, B. Wang, C. Knobler, H. Furukawa, M. O'Keeffe and O. M. Yaghi, Science, 2008, 319, 939-943. K. Noh, J. Lee and J. Kim, Isr. J. Chem., 2018, 58, 10751088.

R. Gaillac, P. Pullumbi and F. X. Coudert, J. Phys. Chem. C, 2018, 122, 6730-6736.

T. D. Bennett, J. C. Tan, Y. Yue, E. Baxter, C. Ducati, N. J. Terrill, H. H. M. Yeung, Z. Zhou, W. Chen, S. Henke, A. K. Cheetham and G. N. Greaves, Nat. Commun., 2015, 6, 1-7. L. Frentzel-Beyme, M. Kloß, R. Pallach, S. Salamon, H. Moldenhauer, J. Landers, H. Wende, J. Debus and S. Henke, J. Mater. Chem. A, 2019, 7, 985-990.

L. Frentzel-Beyme, M. Kloß, P. Kolodzeiski, R. Pallach and S. Henke, J. Am. Chem. Soc., 2019, 141, 12362-12371. Y. Zhao, S. Y. Lee, N. Becknell, O. M. Yaghi and C. A. Angell, J. Am. Chem. Soc., 2016, 138, 10818-10821.

C. Zhou, L. Longley, A. Krajnc, G. J. Smales, A. Qiao, I. Erucar, C. M. Doherty, A. W. Thornton, A. J. Hill, C. W. Ashling, O. T. Qazvini, S. J. Lee, P. A. Chater, N. J. Terrill, A. J. Smith, Y. Yue, G. Mali, D. A. Keen, S. G. Telfer and T. D. Bennett, Nat. Commun., 2018, 9, 1-9.

T. D. Bennett, A. L. Goodwin, M. T. Dove, D. A. Keen, M. G. Tucker, E. R. Barney, A. K. Soper, E. G. Bithell, J. C. Tan and A. K. Cheetham, Phys. Rev. Lett., 2010, 104, 11503. R. Lehnert and F. Seel, Z. Anorg. Allg. Chem., 1980, 464, 
187-194.

T. Wu, X. Bu, J. Zhang and P. Feng, Chem. Mater., 2008, 20, 7377-7382.

41 J. B. James and Y. S. Lin, J. Phys. Chem. C, 2016, 120, 14015-14026.

42 M. L. Ríos Gómez, G. I. Lampronti, Y. Yang, J. C. Mauro and T. D. Bennett, Dalt. Trans., 2020, 49, 850-857.

43 J. Hou, M. L. Ríos Gómez, A. Krajnc, A. McCaul, S. Li, A. M. Bumstead, A. F. Sapnik, Z. Deng, R. Lin, P. A. Chater, D. S. Keeble, D. A. Keen, D. Appadoo, B. Chan, V. Chen, G. Mali and T. D. Bennett, J. Am. Chem. Soc., 2020, 142, 38803890. L. Palatinus and G. Chapuis, J. Appl. Cryst., 2007, 40, 786790.

45 G. M. Sheldrick, Acta Cryst., 2015, C71, 3-8.

L. J. Farrugia, J. Appl. Cryst., 2012, 45, 849-854.

R. N. Widmer, G. I. Lampronti, S. Anzellini, R. Gaillac, S. Farsang, C. Zhou, A. M. Belenguer, C. Wilson, H. Palmer, A. K. Kleppe, M. T. Wharmby, X. Yu, S. M. Cohen, S. G. Telfer, S. A. T. Redfern, F. X. Coudert, S. G. Macleod and T. D. Bennett, Nat. Mater., 2019, 18, 370-376. R. N. Widmer, G. I. Lampronti, S. Chibani, C. W. Wilson, S. Anzellini, S. Farsang, A. K. Kleppe, N. P. M. Casati, S. G. Macleod, S. A. T. Redfern, F. X. Coudert and T. D. Bennett, J. Am. Chem. Soc., 2019, 141, 9330-9337. S. Li, R. Limbach, L. Longley, A. Shirzadi, J. C. Walmsley, D. N. Johnstone, P. A. Midgley, L. Wondraczek and T. D. Bennett, J . Am. Chem. Soc., 2019, 141, 1027-1034. A. Qiao, T. D. Bennett, H. Tao, A. Krajnc, G. Mali, C. M. Doherty, A. W. Thornton, J. C. Mauro, G. N. Greaves and Y. Yue, Sci. Adv., 2018, 4, 1-7. A. A. Coelho, TOPAS-Academic (Version 6), Coelho Software, Brisbane, 2016. Bruker, TopSpin (Version 4.0.7), Bruker, Billerica, MA, 2019. A. K. Soper and E. R. Barney, J. Appl. Crystallogr., 2011, 44, 714-726.

A. K. Soper, Sci. Technol. Facil. Counc. Tech. Rep. RAL-TR2011-013, 2011, 1-135. D. Peralta, G. Chaplais, A. Simon-Masseron, K. Barthelet and G. D. Pirngruber, Microporous Mesoporous Mater., 2012, 153, 1-7.

56 A. Bondi, J. Phys. Chem., 1964, 68, 441-451.

57 J. Yang, Y. B. Zhang, Q. Liu, C. A. Trickett, E. GutiérrezPuebla, M. Á. Monge, H. Cong, A. Aldossary, H. Deng and O. M. Yaghi, J. Am. Chem. Soc., 2017, 139, 6448-6455. C. Zhou, M. Stepniewska, L. Longley, C. W. Ashling, P. A. Chater, D. A. Keen, T. D. Bennett and Y. Yue, Phys. Chem. Chem. Phys., 2018, 20, 18291-18296. J. Catalán, R. M. Claramunt, J. Elguero, J. Laynez, M. Menéndez, F. Anvia, J. H. Quian, M. Taagepera and R. W. Taft, J. Am. Chem. Soc., 1988, 110, 4105-4111. D. W. Lewis, A. R. Ruiz-Salvador, A. Gómez, L. M. Rodriguez-Albelo, F.-X. Coudert, B. Slater, A. K. Cheetham and C. Mellot-Draznieks, CrystEngComm, 2009, 11, 2272.
L. S. Bartell, J. Am. Chem. Soc., 1959, 81, 3497-3498. L. Longley, S. M. Collins, G. J. Smales, I. Erucar, A. Qiao, J. Hou, C. M. Doherty, A. Thornton, A. J. Hill, X. Yu, N. J. Terrill, A. J. Smith, S. M. Cohen, P. A. Midgley, D. A. Keen, S. G. Telfer and T. D. Bennett, Chem. Sci., 2019, 10, 35923601. 